\title{
Eco-friendly Modified Silicone Poly-Acrylate Binder Synthesis and Application of Textiles Pigment Printing
}

\author{
Mohammad Raza Miah ${ }^{1, ~ *, ~ Z a k a r i a ~}{ }^{1}$, Asaduzzaman ${ }^{1}$, Md Forhad Hossain ${ }^{1}$, \\ Md Kamrul Hasan Munna ${ }^{2}$ \\ ${ }^{1}$ Department of Chemistry \& Chemical Engineering, Wuhan Textile University, Wuhan, P.R. China \\ ${ }^{2}$ Department of Textile Engineering, Wuhan Textile University, Wuhan, P.R. China
}

Email address:

razamiah2012@gmail.com (M. R. Miah)

${ }^{*}$ Corresponding author

\section{To cite this article:}

Mohammad Raza Miah, Zakaria, Asaduzzaman, Md Forhad Hossain, Md Kamrul Hasan Munna. Eco-friendly Modified Silicone PolyAcrylate Binder Synthesis and Application of Textiles Pigment Printing. American Journal of Applied Chemistry.

Vol. 4, No. 5, 2016, pp. 201-206. doi: 10.11648/j.ajac.20160405.17

Received: August 18, 2016; Accepted: September 26, 2016; Published: October 25, 2016

\begin{abstract}
Modified silicone environmental- friendly poly-acrylate binder was prepared by emulsion polymerization technique using soft, hard, functional monomers. Newly synthesized binder was applied on fabric by pigment printing techniques. It was carried out on lab scale by simple screen printing techniques. We have synthesized this binder by using organic silicone, initiator, emulsifier, $\mathrm{P}^{\mathrm{H}}$ adjustor, deionized water and ammonia water as required. Binder should be soft, good film, high strength, good elasticity, excellent wash ability, strong adhesion, light color, excellent transparency and excellent light fastness, low cost and easy to implement production. Also get positive test results such as rubbing (wet $\&$ dry) fastness, water resistance of the film, softness, significant flexibility and staining resistance.
\end{abstract}

Keywords: Eco-friendly, Polymer Synthesis, Silicone Modified, Poly-acrylate, Pigment Printing Binder, Textiles Printing

\section{Introduction}

Cotton is one of the most important fibers in the textile industry and its coloration could be achieved with either dyes, by dyeing or printing in aqueous solution or with pigment by using a print paste. Printing of cellulosic fibers are considered to account for more than $70 \%$ of all printed substrates and pigment printing is a major method [1]. The use of pigments for printing of textile products has dramatically increased over the last 50 years. Pigments are used to produce printed products for a number of end uses including apparels, home furnishing, crafts and nonwoven articles of the over 18 billion liners yards of printed fabric produced worldwide each years, about $50 \%$ of this yardage is pigment printed. In the united states alone, currently about $80 \%$ of all printing is done with pigment [2]. There are of course limitations to balance against the substantial advantages of pigment printing. The printer should be fully aware of these, since the use of pigments in applications where dyes are required can bring about a negative attitude to pigments, even in suitable applications [3]. In pigment printing, insoluble pigments, which have no affinity for fibers, are fixed on to the fibers with binding agents or binders [4]. Depending upon the properties required in the binding film (softness, elasticity, plasticity, solvent stability), binders can be tailor-made by choosing suitable base product. It is necessary to copolymerize different monomers. Typically, unsaturated monomers are used, such as vinyl chloride, dichloroethene, acrylonitrile, acrylic acid, esters and others. The binder used in the pigment printing process is usually based on styrene-butadiene, styrene acrylate or vinyl acetate acrylate copolymer [5]. Pigment printing technology of textiles has been applied widely because of its simple operation techniques, complete color and excellent fastness [6]. Generally, poly-acrylate, polybutadiene, polyvinyl acetate and polyurethane all can be used as pigment printing binder. Of course, poly-acrylate dispersion is the most prevalent one, nevertheless contained 
formaldehyde, highly hardness, inferior heat and cold resistance result pollution and worse application properties $[7,8]$. Very small amounts are required to achieve the desired properties, which offer cost effective textile operations and ensure negligible environmental impact [9, 10]. Both outstanding properties of the binder as well as silicon addition to the pigment printing fabric contribute to crock fastness, good mechanical properties and resisting deformation of the coating on rubbing [11]. Organic silicone based textile binder, make not only fabric soft and smooth but also good elastic properties \& increase the added value of the fabric [12]. The amount of silicon is explores during the preparation of binder by significantly. Observing resultant impact on polymer quality like solid content, gel ratio, polymer conversion rates, acid and alkali stability, electrolyte resistance stability etc. as well as resultant impact on printed fabric quality like dry \& wet rub fastness, sublimation test $[13,14]$ (Table 1) Properties of the monomer on the film: We select acrylic acid and hydroxyl-ethyl acrylate as a functional monomer due to its higher water solubility. [15]

Table 1. Properties of the monomer on the film: We select acrylic acid and hydroxyl-ethyl acrylate as a functional monomer due to its higher water solubility. [15].

\begin{tabular}{|c|c|c|c|c|c|c|c|c|}
\hline $\begin{array}{l}\text { Type of } \\
\text { Monomer }\end{array}$ & Single body & Elasticity & Softness & Washable & $\begin{array}{l}\text { Resistant to } \\
\text { solvents Agent }\end{array}$ & $\begin{array}{l}\text { Heat } \\
\text { resistance }\end{array}$ & $\begin{array}{l}\text { Dry rub } \\
\text { resistance }\end{array}$ & $\begin{array}{l}\text { Wet rub } \\
\text { resistance }\end{array}$ \\
\hline Soft monomer & Ethyl acrylate & ○ & ० & $\circ \sim \Delta$ & ० & $*$ & $\nearrow$ & $\searrow$ \\
\hline \multirow{2}{*}{$\begin{array}{l}\text { Hard } \\
\text { monomer }\end{array}$} & Styrene & $\searrow$ & $\searrow$ & $\rightarrow$ & $\searrow$ & $\rightarrow$ & $\nearrow$ & $\nearrow$ \\
\hline & Acrylonitrile & $\searrow$ & $\searrow$ & $\searrow$ & $\nearrow$ & $\searrow$ & $\nearrow$ & $\nearrow$ \\
\hline
\end{tabular}

Note: * Excellent; $\circ$ good; $\Delta$ general; $\times$ bad; $\nearrow$ increase; $\rightarrow$ unchanged; $\searrow$ decline.

\section{Objectives}

- The aim of our task is to synthesize a good quality of binder which can be used for pigment printing process.

- The binder should be stable and not be degraded in the fabric during storage and use.

\section{Binder Properties}

- The binder should be stable and not be degraded in the fabric during storage and use.

- Binder must have the soft handle properties.

- Binder should have good elastic recovery under strain.

- The adhesion strength of the binder to fiber bond has to be considered.

- A suitable binder should have also some other properties like strength, firmness, durability, stiffness, hydrophobicity, anti- microbial properties, organic compatibility, reduced surface tension, improved dimensional stability, wash and acid resistance.

\section{Chemical Structure of Standard Silicones (Figure 1)}<smiles>[Y][Si](C)(C)O[Si](C)(C)O[Si](C)(C)OC</smiles>

Figure 1. Standard Silicones.

\section{Chemical Structure of Modified Silicone Poly-Acrylate Binder (Figure 2)}

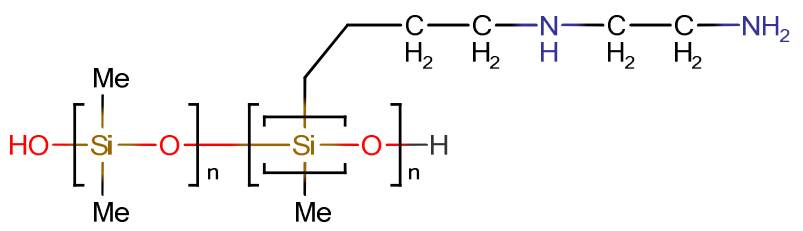

Figure 2. Modified Silicone.

\section{Advantage of Poly -Acrylate Binder}

- Binder is monomers which on heating get converted into polymers.

- Binder actually holds the pigment color on fabric surface.

- Binder creates plastic coating and this coating help color to stick conditions.

\section{Properties of Pigment Printing Binder}

- The softness and strength of the binder film can be adjusted according to the ratio of soft and hard monomers.

- Physical appearance should be transparent

- PH should be 7 to 8 . And Cons. $33 \% \pm 1 \%$ polymer contains \& 38\% $\pm 1 \%$ Solids.

- Good resistant ability to solvent.

- Good rubbing fastness (wet \& dry)

\subsection{Monomer}

A molecule of any of a class of compounds, mostly organic, that can react with other molecules of the same or 
other compound to form very large molecules, or polymers. The essential feature of a monomer is poly-functionality, the capacity to form chemical bonds to at least two other monomer molecules. Bi-functional monomers can form only linear, chainlike polymers, but monomers of higher functionality yield cross-linked, network polymeric products.

"So monomer is a simple compound whose molecules can join together to form polymers."

\subsection{Monomer and Types of Monomers}

The monomer can be categorized into three classes.

- Soft monomers:

Soft monomers, characterized by lower Tg values. These monomers are longer chain alkyl acrylates and exhibit low water solubility (i.e., high hydrophobicity).

Examples: Butyl acrylate, Ethyl acrylate, Methyl acrylate and iso-octyl acrylate.

Properties: We select Ethyl acrylate and Butyl acrylate as soft monomers which improve adhesive film flexibility and elasticity.

- Hard monomers:

Hard monomers, characterized by higher Tg values. The hydrophobicity of the hard monomer depends on the monomer structure

Examples: Styrene, Methyl Methacrylate and Acrylonitrile.

\subsection{Recipe of Poly Acrylate Binder [Table 2(a and b)]}

Properties: We select styrene and acrylonitrile as a hard monomer providing structural strength, wear resistance, washing resistance so that the transparency of the cured film good, high fastness.

- Functional Monomers:

The third class is the functional monomer with various functional groups, such as carboxyl or hydroxyl which are very water-soluble.

Examples: Acrylic acid and Hydroxy-ethyl Acrylate.

\section{Experimental}

\subsection{Materials}

$100 \%$ cotton woven bleached fabric construction $(40 s \times 40 s, 110 \times 90)$ was used for pigment printing purpose.

\subsection{Instruments \& Reagents}

Instrument using for binder: Electric blender, Round bottom flask, Electric heating system using by water bath, Initiator control by dropper, $\mathrm{P}^{\mathrm{H}}$ control by $\mathrm{P}^{\mathrm{H}}$ paper and also using color measurement instrument(SF 600), Crock master (Y571N)

Instrument \& Reagents for Pigment Printing: Using rotary screen printing method, Pigment, Poly-acrylate binder, Thickener, Distilled water as required.

Table 2(a). Poly-acrylate Binder was prepared according to the following recipe.

\begin{tabular}{ll}
\hline Name of the monomers & Amount of chemicals (gm) \\
\hline Ethyl Acrylate(EA) & 30 \\
Styrene(ST) & 15 \\
Methyl Methacrylate(MMA) & 30 \\
Butyl acrylate(BA) & 21 \\
Acrylic Acid(AA) & 2 \\
N-Hydroxyethyl acrylate(NMA) & 2 \\
Total & 100 \\
\hline
\end{tabular}

Table 2(b). Poly-acrylate Binder was prepared according to the following recipe.

\begin{tabular}{ll}
\hline Initiator & Amount of chemicals \\
\hline Ammonium per sulfate (APS) & $0.6 \%$ \\
Emulsifier & Amount of chemicals \\
Potassium Hydroxide $\left(\mathrm{K}_{12}\right)$ & $1.4 \%$ \\
AEO - 9 & $2.6 \%$ \\
Water & $124 \mathrm{ml}$ \\
\hline
\end{tabular}

\subsection{Synthesis of Modified Silicone Poly-Acrylate Binder}

Step I $\rightarrow 20 \%$ of total water, then add emulsify the monomer with surfactants at room temperature with continuous stirring.

Step II $\rightarrow$ Take AEO- 9 and K-12 about 15 minutes at room temperature with continuous stirring.

Step III $\rightarrow$ Then run and put the monomer BA stirring at 10 minutes; After 10 minutes we need add ST EA and MMA; Then added NMA with stirring 40 minutes.

Step IV $\rightarrow$ Take out 5/6 parts pre-emulsion in a bottle; add remaining $80 \%$ of total water and then raises the temp. With continuous stirring. At temp $75-80^{\circ} \mathrm{C}$, add $1 / 3$ parts of initiators in the $1 / 6$ pre-emulsion solutions and run about 20 minutes. Continue the process till for observing the blue beam in mixtures solutions.

Step $\mathrm{V} \rightarrow$ When blue beam observed then remaining $5 / 6$ parts of pre-emulsion and $2 / 3$ parts of initiators put into the reactor simultaneously one by one in 90 minutes of time intervals at $78-82^{\circ} \mathrm{C}$ temp and stirring 30 minutes.

Step VI $\rightarrow$ Added the rest of $1 / 6$ APS and increase the temp from $80^{\circ} \mathrm{C}$ to $85^{\circ} \mathrm{C}$ and keep it about 60 minutes. Until the sweet smell appears. (Note: If sweet smell not found or strong smell observed then add $10 \%$ extra initiators to the 
mixtures. Need to run another $20 \mathrm{~min}$. at $85^{\circ} \mathrm{C}$ ).

Step VII $\rightarrow$ When sweet smell is observed, cooling down at $40^{\circ} \mathrm{C}$.Nuetralize the solutions by adding ammonia water

\subsection{Characterization of Modified Silicone Poly-Acrylate Binder}

\subsubsection{Solid Content}

The following are the testing methods to access the character of the synthesized binder.

$$
\begin{aligned}
\text { Solid Content } & =\left\{\left(\mathrm{G}_{1} / \mathrm{G}_{0}\right) \times 100\right\} \% \\
& =[\{100 /(100+144)\} \times 100] \% \\
& =\{0.4098 \times 100\} \% \\
& =40.98 \%
\end{aligned}
$$

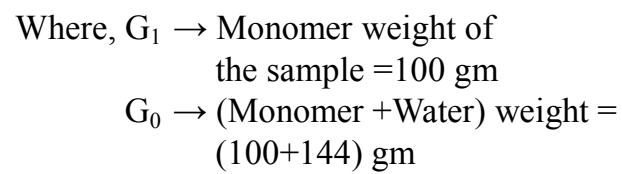

\subsubsection{Gel Ratio}

After completion of the reaction, filter the emulsion collecting all gels, rinse, and baked in an oven at $120^{\circ} \mathrm{C}$ for 2 hours, cooled to room temperature in a desiccator, weighed and the gel fraction is calculated according to formula:

$$
\begin{aligned}
\text { Gel Ratio } & =\{(\mathrm{M} / \mathrm{G}) \times 100\} \% \\
& =\{(0.30 / 100) \times 100\} \% \\
& =0.30 \%
\end{aligned}
$$

Where, $\mathrm{M} \rightarrow$ Dry weight of total Residue

$\mathrm{G} \rightarrow$ Total weight of monomer

\subsubsection{Monomer Conversion Ratio (Table 3)}

Draw 1 to $2 \mathrm{~g}$ emulsion to clean the weighing bottle, add 1 to 2 drops of a solution of hydroquinone, and baked in an oven at $120^{\circ} \mathrm{C}$ for 2 hours, cooled to room temperature in a desiccator. Weighing, the monomer conversion rate was calculated according to formula:

$$
\mathrm{C}=\left[\left\{\mathrm{W}\left(\mathrm{W}_{2}-\mathrm{W}_{1}\right) / \mathrm{G}_{\mathrm{N}}-\mathrm{Y}\right\} / \mathrm{G} 100\right] \%
$$

Where, $\mathrm{C} \rightarrow$ Monomer conversion Ratio,

$\mathrm{W}_{2} \rightarrow$ Weight of Dried bottle,

$\mathrm{W}_{1} \rightarrow$ Weight of empty bottle,

$\mathrm{W} \rightarrow$ Weight of material,

$\mathrm{Y} \rightarrow$ Weight of non-volatile matter in the emulsion, $\mathrm{G}_{\mathrm{N}} \rightarrow$ To learn weight of emulsion, $\quad \mathrm{G} \rightarrow$ Total weight of monomer.

Table 3. Polymerization time on the poly-acrylate binder.

\begin{tabular}{ll}
\hline Polymerization time (min) & Monomer conversion Ratio (\%) \\
\hline 0 & 96.5 \\
30 & 95.5 \\
80 & 95.0 \\
100 & 94.0 \\
150 & 93.0 \\
180 & 97.0 \\
240 & 91.0 \\
\hline
\end{tabular}

\subsubsection{Calculation of Tg Value for Modified Silicone Poly-Acrylate Binder}

Where,

$\mathrm{W}_{1}, \mathrm{~W}_{2}, \mathrm{~W}_{3} \ldots \ldots \mathrm{W}_{\mathrm{n}}$ are weight of respective monomer \&

$\mathrm{T}_{\mathrm{g} 1}, \mathrm{Tg}_{2}, \mathrm{Tg}_{3} \ldots \ldots \mathrm{T}_{\mathrm{gn}}$ are glass transition temperature of respective monomer.

We can calculate the glass transition temperature of poly acrylate binder by using the following equation:

$$
\frac{1}{T g}=\frac{W_{1}}{T g_{1}}+\frac{W_{2}}{T g_{2}}+\cdots \cdots+\frac{W_{n}}{T g_{n}}
$$

Here, $\mathrm{W}_{1}, \mathrm{~W}_{2}, \mathrm{~W}_{3} \ldots \ldots \mathrm{W}_{\mathrm{n}}$ are weight of respective monomer

Weight of Ethyl Acrylate (EA), $\mathrm{W}_{1}$

Weight of Styrene (ST), $\mathrm{W}_{2}$

Weight of Methyl Methacrylate (MMA), $\mathrm{W}_{3}$

Weight of Butyl Acrylate (BA), $\mathrm{W}_{4}$

Weight of Acrylic Acid (AA), $\mathrm{W}_{5}$

Weight of N- Hydroxy Methyl Acrylamide), $\mathrm{W}_{6}$

$\& \mathrm{~T}_{\mathrm{g} 1}, \mathrm{Tg}_{2}, \mathrm{Tg}_{3} \ldots \ldots \mathrm{T}_{\mathrm{gn}}$ are glass transition temperature of respective monomer

$$
\begin{aligned}
& =30 \mathrm{gm} . \\
& =15 \mathrm{gm} . \\
& =30 \mathrm{gm} . \\
& =21 \mathrm{gm} . \\
& =2 \mathrm{gm} . \\
& =2 \mathrm{gm} .
\end{aligned}
$$


Glass transition temperature of Ethyl Acrylate (EA), $\mathrm{Tg}_{1}$

Glass transition temperature of Styrene (ST), $\mathrm{Tg}_{2}$

Glass transition temperature of Methyl Methacrylate (MMA), $\mathrm{Tg}_{3}$

Glass transition temperature of A Butyl Acrylate (BA), $\mathrm{Tg}_{4}$

Glass transition temperature of Acrylic Acid (AA), $\mathrm{Tg}_{5}$

Glass transition temperature of N- Hydroxy Methyl Acrylamide), $\mathrm{Tg}_{6}$

We know that,

$$
\begin{aligned}
& =252 \mathrm{~K} \\
& =373 \mathrm{~K} \\
& =378 \mathrm{~K} \\
& =224 \mathrm{~K} \\
& =376 \mathrm{~K} \\
& =258 \mathrm{~K}
\end{aligned}
$$

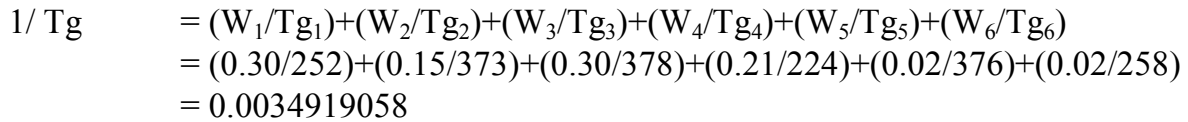

Hence,

$\operatorname{Tg}$

$$
\begin{aligned}
& =289.48 \mathrm{~K} \\
& =16.48^{\circ} \mathrm{C} \text { (within the range of } 10^{\circ} \mathrm{C}<\mathrm{Tg}<25^{\circ} \mathrm{C} \text { ) }
\end{aligned}
$$

\subsubsection{Particle Size Analyzer}

Particle size dispersions measured by laser particle size analyzer. The minimum particle size in the emulsion was around 40 $\mathrm{nm}$ and the maximum particle size was $280 \mathrm{~nm} \&$ the finally distributed average particle size was $120 \mathrm{~nm}$.

\subsubsection{Application of Modified Silicone Poly-Acrylate Binder on 100\% Cotton Woven Bleached Fabric}

The pigment printing pastes were prepared according to the following recipe:

Pigment

Poly-acrylate binder

Thickener

Distilled water

$\mathrm{P}^{\mathrm{H}}$

$$
\begin{aligned}
& 50 \mathrm{~g} / \mathrm{kg} \\
& 15 \mathrm{~g} / \mathrm{kg} \\
& 30 \mathrm{~g} / \mathrm{kg} \\
& \text { As required } \\
& 8-9
\end{aligned}
$$

\begin{tabular}{|c|c|c|c|c|c|c|c|}
\hline \multirow{2}{*}{ No. of Samples } & \multirow{2}{*}{ Sublimation test } & \multirow{2}{*}{ Durability test } & \multicolumn{2}{|c|}{ Rubbing fastness } & \multirow{2}{*}{ Staining resistance } & \multirow{2}{*}{ Yellowing } & \multirow{2}{*}{ Softness $(\mathrm{cm})$} \\
\hline & & & Wet rub & Dry rub & & & \\
\hline 1 & Pass & Pass & 3 & $3-4$ & 2.5 & 14.1 & 6.6 \\
\hline 2 & Pass & Pass & $2-3$ & 3 & 2.4 & 15 & 6.5 \\
\hline 3 & Pass & Pass & $3-4$ & 4 & 2.6 & 14.6 & 6.7 \\
\hline 4 & Pass & Pass & 3 & $3-4$ & 2.5 & 12.2 & 6 \\
\hline 5 & Pass & Pass & $2-3$ & 3 & 2.3 & 15.3 & 6.8 \\
\hline
\end{tabular}

\subsubsection{Printing Method}

The printed fabric dried at $120^{\circ} \mathrm{C}$ for $3 \mathrm{~min}$ and cured at $150^{\circ} \mathrm{C}$ for 2 minutes.

\subsubsection{Evaluation of Color Fastness}

For evaluation of $100 \%$ cotton printed fabrics, the following tests were performed:

- Fastness to rubbing, according to ISO 105-X12

- Sublimation test, Durability test, Staining resistance, Yellowing and Softness test.

\section{Result \& Discussion}

\subsection{Optimization of Testing Methods}

Assessment of the Sublimation test, Durability test, Rubbing (wet \& dry) fastness test, staining resistance, Yellowing and Softness test of a printed fabric and results in (Table 4):

Table 4. Printed fabric performance test.

After testing result we observed pass signal for sublimation and durability test. Then comparatively dry rubbing fastness value is high and yellowing and softness is comparatively satisfied.

\section{Conclusion}

Synthesis and application of eco-friendly modified silicone based poly-acrylate binder was performed in laboratory scale. From the synthesis of this binder we have got lower cost and 
from the application of this binder we have got moderate hand feel $\left(\mathrm{Tg}\right.$ value is $\left.16.48^{\circ} \mathrm{C}\right)$ with good rubbing fastness properties on printed fabric. We have tested our samples according to ISO test standard. The suitable conditions of reaction, maintaining time, temperature and dosage of chemicals help us to get a product with excellent properties.

\section{Acknowledgement}

This work was financially supported by the Wuhan Textile University. We are thankful to Prof. Dr. Heng Quan for his guidance, encouragement and patience throughout this study. The authors gratefully wish to express their also thanks to the reviewers for critically reviewing the manuscript and making important suggestions.

\section{References}

[1] M. M. Molla, "Synthesis of Polyurethane Acrylate Oligomers as Aqueous UV-Curable Binder for Inks Jet in Textile Printing and Pigment Dyeing," Dyes and Pigments, Vol. 74, No. 10, 2007, pp. 371-379. doi: 10.1016/j. dyepig. 2006.02.021

[2] K. Oza and K. Shah, "Aqueous System for Pigment Printing," Textile Dyers and Printers, Vol. 21, No. 11, 1988, pp. 21-25.

[3] A. Poehlmann, "Pigment Printing System," Textile Industries Dyegist, Vol. 11, No. 10, 1992, pp. 4-9.

[4] R. M. Christie, "The Chemistry of Color Application," 1st Edition, Blackwell Science, England, 2000.

[5] W. C. Miles, "Textile Printing," 2nd Edition, Society of Dyers and Colorist, Bradford England, 2004.

[6] Galgali: Colourage Vol. 45, 1998, P. 20-22.

[7] Z. Yang, Y. D.Wang, H. Quan: Textile Auxiaries (in Chinese) Vol. $28(2011,2)$, P. 29-32

[8] R.B Chavan: Indian J. Fiber Text.Res. Vol. 19 (1994, 3), P. 2223.

[9] Marchi.: Spreparation and characterization of silicone Nano composites by UV-induced hydrosilation for outdoor polymeric insulators.(2014)

[10] Kang TJ, Kim MS: Effects of silicone treatments on the dimensional properties of wool fabric, Textile Research journal. 2001,71: 295-300

[11] HUANG F, LIN Z-x: Preparation of amino silicone oil modified core-shell structure pigment printing binder [j].Chemistry and Adhesion. 2005, 6:007.

[12] YUAN P-r, HE H.: Preparation of pigment printing binder for environmental protection[j]. Guangzhou Chemical Industry. 2006, 2:018.

[13] LIU F-f, HUANG W-j.: Synthesis and characterization of a new pigment printing adhesive[j]. Textile Auxiliaries. 2005, 10: 002 .

[14] XIAO J-h, YU H, SONG X-y: Synthesis and characterization of environmentally friendly low temperature self-crosslinking printing binder[j]. Textile Auxiliaries. 2000, 6:007.

[15] YANG Z, QUAN H. Preparation craft and application performance of poly-acrylate binder for pigment printing [j].Textile Auxiliaries. 2009, 3: 011.

\section{Biography}

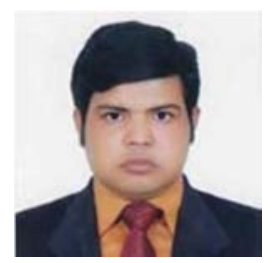

Mohammad Raza MIAH is currently working as a graduate research assistant at Wuhan Textile University at the Dyeing and Finishing section of the research in School of Chemistry and Chemical Engineering. He is a holder of MSc in Textile Engineering (Dyeing and Finishing) in "Eco-friendly Modified Silicone PolyAcrylate Binder Synthesis and Application of Textiles Pigment Printing" at the School of Chemistry and Chemical Engineering, Faculty of Engineering, Wuhan Textile University, Wuhan, Hubei, China. His main research interest is in; eco-friendly coating agent invention and application on textiles. Also his ongoing research is in; eco-friendly dyeing of natural dye sensitized by solar cells and QSPR study on absorption maxima. 